\title{
Treating the mind to improve the heart: the summon to cardiac psychology
}

\author{
J. P. Ginsberg ${ }^{1 *}$, Giada Pietrabissa ${ }^{2,3}$, Gian Mauro Manzoni ${ }^{2,3}$ and \\ Gianluca Castelnuovo ${ }^{2,3}$ \\ ${ }^{1}$ Research and Development, Cardiopsychology Research Laboratory, Dorn VA Medical Center, Columbia, SC, USA, \\ ${ }^{2}$ Psychology Research Laboratory, Istituto Auxologico Italiano IRCCS, Ospedale San Giuseppe, Verbania, Italy, ${ }^{3}$ Department \\ of Psychology, Catholic University of Milan, Italy
}

Keywords: HRV, heart rate variability, cardiac psychology, autonomic control of cardiovascular system, stress, psychological, PTSD

OPEN ACCESS

Edited by:

Omar Carlo Gioacchino Gelo, Universita del Salento/Sigmund Freud

University, Italy

Reviewed by: Rollin McCraty,

Institute of HeartMath, USA

Xavier Bornas,

University of the Balearic Islands,

Spain

*Correspondence:

J. P. Ginsberg,

jay.ginsberg@va.gov

Specialty section:

This article was submitted to

Psychology for Clinical Settings,

a section of the journal

Frontiers in Psychology

Received: 27 May 2015

Accepted: 17 July 2015

Published: 04 August 2015

Citation:

Ginsberg JP, Pietrabissa G, Manzoni GM and Castelnuovo G (2015)

Treating the mind to improve the

heart: the summon to cardiac psychology. Front. Psychol. 6:1101.

doi: 10.3389/fpsyg.2015.01101
The link between the heart and mind has been studied over the centuries in many fields, such as medicine and psychology (Thayer and Lane, 2009; Allan, 2012). Different terms have been used recently to identify this research and clinical area: e.g., Behavior Cardiology (Rozanski et al., 2005), Psychocardiology (Jordan et al., 2007), and Cardiac Psychology (Allan, 2012). Many risk factors for coronary heart disease have been studied: thus, age, gender, and family history are considered as typical unmodifiable risk factors, whereas diabetes, weight, life stress, type A behavior, social isolation, depression, sedentary lifestyle, cholesterol/HDL ratio, hypertension, and cigarette smoking are the typical modifiable and clinically treatable risk factors (Allan, 2012).

Mental stress is now also recognized as a risk factor in cardiac dysregulation. Due to an "epigenetic psychobiologic susceptibility-the nexus of psychophysiologic reactivity and biopsychosocial vulnerability" (Fischer and Collins, 2012, p. 58), acute emotional traumas could "trigger a panic attack in some and transient or permanent cardiac damage or life-threatening arrhythmias or death in others" (Fischer and Collins, 2012, p. 58). Moreover mental stress could be an important trigger of cardiovascular events with clinical relevance, taking into account that stress responses can be mediated or moderated by psychological variables, such as coping skills or personality characteristics, and by social aspects such the presence of family or systemic support (Krantz et al., 2012). In many situations multiple stressors could be involved in generating cardiovascular events (Menezes et al., 2011). Natural calamities, such as earthquakes, and human-made extreme disasters, such as war and terrorism, can precipitate cardiovascular events (Mittleman and Mostofsky, 2012).

A typical field of intervention for the Cardiac Psychology is Posttraumatic Stress Disorder (PTSD), classified as an anxiety disorder in the latest version of Diagnostic and Statistical Manual of Mental Disorders (American Psychiatric Association, 2013). The essential feature of PTSD is the development of specific symptoms, following exposure to one or more traumatic events, such as recurrent and intrusive memories or dreams about the trauma (re-experiencing symptoms), flashbacks, emotional numbing, or heightened physiologic arousal. PTSD affects significant organic outcomes too (Doerfler and Paraskos, 2012). A typical example is reported in Shemesh et al. (2004), where a group of patients with PTSD followed one year after a myocardial infarction (MI) were more than twice as likely to be submitted to another hospitalization because of cardiovascular reasons than individuals with MI but without PTSD. Taking into account that many effective interventions are available nowadays to treat and reduce PTSD in different populations (Arnberg and Johannesson, 2013; Barrera et al., 2013; Gillies et al., 2013; Warner et al., 2013; Cukor and Difede, 2014), it appears to be the case that research into cardiac effects of PTSD is not highly developed, in fact in 2012 Doerfler wrote that "Research on CBT (Cognitive Behavioral Therapy) 
for cardiac-related PTSD is in its infancy, and the literature consists of only a few uncontrolled case studies, but these reports may be instructive in stimulating treatment development" (Doerfler and Paraskos, 2012, p. 260).

So the study of psychosocial factors and interventions in the field of Cardiac Psychology and PTSD is a growing need and challenge in our clinical and scientific community (Ginsberg et al., 2008, 2010; Chen et al., 2014; Conder and Conder, 2014; Drury, 2014; Gillie and Thayer, 2014; Lee et al., 2014; Lehrer and Gevirtz, 2014; Mccraty and Zayas, 2014; Shaffer et al., 2014; Steffen et al., 2014; Wood, 2014). In cardiovascular rehabilitation protocols it is important to evaluate different clinical psychology-based program types, such as psychological interventions, psycho-educational programs, psychotherapies, educational training, stress management, biofeedback, counseling sessions and relaxation techniques (Jordan et al., 2007; Dornelas, 2008, 2012; Manzoni et al., 2008; Castelnuovo, 2010a,b). New approaches have to be tested, such as Acceptance and Commitment Therapy (Spatola et al., 2014a,b)

\section{References}

Allan, R. (2012). "The evolution of cardiac psychology," in Heart and Mind: The Practice of Cardiac Psychology, eds R. Allan and J. Fischer (Washington, DC: American Psychological Association), 3-13.

American Psychiatric Association. (2013). Diagnostic and Statistical Manual of Mental Disorders, 5th Edn. Washington, DC.

Arnberg, F. K., and Johannesson, K. B. (2013). [Posttraumatic stress: what we should do after adverse life events]. Lakartidningen 110, 95-98.

Barrera, T. L., Mott, J. M., Hofstein, R. F., and Teng, E. J. (2013). A meta-analytic review of exposure in group cognitive behavioral therapy for posttraumatic stress disorder. Clin. Psychol. Rev. 33, 24-32. doi: 10.1016/j.cpr.2012. 09.005

Capodaglio, P., Castelnuovo, G., Brunani, A., Vismara, L., Villa, V., Capodaglio, E. M. et al. (2010). Functional limitations and occupational issues in obesity: a review. Int. J. Occup. Saf. Ergon 16, 507-523.

Capodaglio, P., Lafortuna, C., Petroni, M. L., Salvadori, A., Gondoni, L., Castelnuovo, G., et al. (2013). Rationale for hospital-based rehabilitation in obesity with comorbidities. Eur. J. Phys. Rehabil. Med. 49, 399-417.

Castelnuovo, G., Gaggioli, A., Mantovani, F., and Riva, G. (2003). From psychotherapy to e-therapy: the integration of traditional techniques and new communication tools in clinical settings. Cyberpsychol. Behav. 6, 375-382. doi: $10.1089 / 109493103322278754$

Castelnuovo, G., Pietrabissa, G., Manzoni, G. M., Spatola, C. A., Cappella, E. M., Baruffi, M., et al. (2014). The need of psychological motivational support for improving lifestyle change in cardiac rehabilitation. Exp. Clin. Cardiol. 20, 4856-4861.

Castelnuovo, G., and Simpson, S. (2011). Ebesity - e-health for obesity - new technologies for the treatment of obesity in clinical psychology and medicine. Clin. Pract. Epidemiol. Ment. Health 7, 5-8. doi: 10.2174/17450179011070 10005

Castelnuovo, G. (2010a). Empirically supported treatments in psychotherapy: towards an evidence-based or evidence-biased psychology in clinical settings? Front. Psychol. 1:27. doi: 10.3389/fpsyg.2010.00027

Castelnuovo, G. (2010b). No medicine without psychology: the key role of psychological contribution in clinical settings. Front. Psychol. 1:4. doi: 10.3389/fpsyg.2010.00004

Cazard, F., and Ferreri, F. (2013). [Bipolar disorders and comorbid anxiety: prognostic impact and therapeutic challenges]. Encephale 39, 66-74. doi: 10.1016/j.encep.2012.04.005

Chen, K. -H., Aksan, N., Anderson, S. W., Grafft, A., and Chapleau, M. W. (2014). Habituation of parasympathetic-mediated heart rate responses to or expressive writing (Manzoni et al., 2011a), improving the study of rehabilitation programs on patients with comorbidities such as obesity (Manzoni et al., 2011b; Pietrabissa et al., 2012), improving the study of psychosocial and cognitive features related to the cardiac pathology with or without complications (Capodaglio et al., 2010, 2013; Manzoni et al., 2010, 2011a; Proietti et al., 2012, 2014; Cazard and Ferreri, 2013; Castelnuovo et al., 2014), and opening to the growing opportunities provided by new technologies and mHealth approach (Castelnuovo et al., 2003, 2014; Nguyen et al., 2004; Rubel et al., 2005; Riva et al., 2006; Roth et al., 2009; Castelnuovo and Simpson, 2011).

The study of the relationship of autonomic cardiac adjustment to stress and mental disorder-the heart-mind connectionis the challenge that Cardiac Psychology has accepted. This Frontiers Research Topic special is devoted to providing a foundation for the development of the scientific study of these relationships, and the discovery of the propositions that govern them.

recurring acoustic startle. Front. Psychol. 5:1288. doi: 10.3389/fpsyg.2014 01288

Conder, R. L., and Conder, A. A. (2014). Heart rate variability interventions for concussion and rehabilitation. Front. Psychol. 5:890. doi: 10.3389/fpsyg.2014.00890

Cukor, J., and Difede, J. (2014). Review: psychotherapy, somatic therapy and pharmacotherapy are all more effective than control for the treatment of PTSD. Evid. Based Ment. Health 17, 7. doi: 10.1136/eb-2013-101527

Doerfler, L. A., and Paraskos, J. A. (2012). "Post traumatic stress disorder following myocardial infarction or cardiac surgery," in Heart and Mind: The Practice of Cardiac Psychology, eds R. Allan and J. Fischer (Washington, DC: American Psychological Association), 249-268.

Dornelas, E. A. (ed.). (2012). Stress Proof the Heart: Behavioral Interventions for Cardiac Patients. New York, NY: Springer.

Dornelas, E. A. (2008). Psychotherapy with Cardiac Patients: Behavioral Cardiology in Practice. Washington, DC: American Psychological Association.

Drury, R. L. (2014). Wearable psychobiologic sensors and resilience as a systems strategy to develop personalized health through the extensive care system: a perfect storm? Front. Psychol. 5:853. doi: 10.3389/fpsyg.2014.00853

Fischer, J., and Collins, D. (2012). "Psychocardiac disorders," in Heart and Mind: The Practice of Cardiac Psychology, eds R. Allan and J. Fischer (Washington, DC: American Psychological Association), 55-90.

Gillie, B. L., and Thayer, J. (2014). Individual differences in resting heart rate variability and cognitive control in posttraumatic stress disorder. Front. Psychol. 5:758. doi: 10.3389/fpsyg.2014.00758

Gillies, D., Taylor, F., Gray, C., O’Brien, L., and D'Abrew, N. (2013). Psychological therapies for the treatment of post-traumatic stress disorder in children and adolescents (Review). Evid. Based Child Health 8, 1004-1116. doi: 10.1002/ebch.1916

Ginsberg, J. P., Ayers, E., Burriss, L., and Powell, D. A. (2008). Disruption of bradycardia associated with discriminative conditioning in combat veterans with PTSD. Neuropsychiatr. Dis. Treat. 4, 635-646. doi: 10.2147/NDT.S2808

Ginsberg, J. P., Berry, M. E., and Powell, D. A. (2010). Cardiac coherence and posttraumatic stress disorder in combat veterans. Altern. Ther. Health Med. 16, 52-60.

Jordan, J., Bardé, B., and Zeiher, A. M., (eds.). (2007). Contributions Toward Evidence-based Psychocardiology: A Systematic Review of the Literature. Washington, DC: American Psychological Association.

Krantz, D., Whittaker, K. S., and Sheps, D. S. (2012). "Psychosocial risk factors for coronary heart disease: pathophysiologic mechanisms," in Heart and Mind: The Practice of Cardiac Psychology, eds R. Allan and J. Fischer (Washington, DC: American Psychological Association), 91-113. 
Lee, S. W., Gerdes, L., Tegeler, C. L., Shaltout, H. A., and Tegeler, C. H. (2014). A bihemispheric autonomic model for traumatic stress effects on health and behavior. Front. Psychol. 5:843. doi: 10.3389/fpsyg.2014.00843

Lehrer, P. M., and Gevirtz, R. (2014). Heart rate variability biofeedback: how and why does it work? Front. Psychol. 5:756. doi: 10.3389/fpsyg.2014.00756

Manzoni, G. M., Castelnuovo, G., and Molinari, E. (2008). Weight loss with a lowcarbohydrate, Mediterranean, or low-fat diet. N.Engl. J. Med. 359, 2171-2172.

Manzoni, G. M., Castelnuovo, G., and Proietti, R. (2011a). Assessment of psychosocial risk factors is missing in the $2010 \mathrm{ACCF} / \mathrm{AHA}$ guideline for assessment of cardiovascular risk in asymptomatic adults. J. Am. Coll. Cardiol. 57, 1569-1570; author reply 1571. doi: 10.1016/j.jacc.2010.12.015

Manzoni, G. M., Cribbie, R. A., Villa, V., Arpin-Cribbie, C. A., Gondoni, L., and Castelnuovo, G. (2010). Psychological well-being in obese inpatients with ischemic heart disease at entry and at discharge from a four-week cardiac rehabilitation program. Front. Psychol. 1:38. doi: 10.3389/fpsyg.2010. 00038

Manzoni, G. M., Villa, V., Compare, A., Castelnuovo, G., Nibbio, F., Titon, A. M., et al. (2011b). Short-term effects of a multi-disciplinary cardiac rehabilitation programme on psychological well-being, exercise capacity and weight in a sample of obese in-patients with coronary heart disease: a practice-level study. Psychol. Health Med. 16, 178-189. doi: 10.1080/13548506.2010.542167

Mccraty, R., and Zayas, M. A. (2014). Cardiac coherence, self-regulation, autonomic stability and psychosocial well-being. Front. Psychol. 5:1090. doi: 10.3389/fpsyg.2014.01090

Menezes, A. R., Lavie, C. J., Milani, R. V., O’Keefe, J., and Lavie, T. J. (2011). Psychological risk factors and cardiovascular disease: is it all in your head? Postgrad. Med. 123, 165-176. doi: 10.3810/pgm.2011.09.2472

Mittleman, M. A., and Mostofsky, E. (2012). "Triggers of myocardial infarction and sudden cardiac death," in Heart and Mind: The Practice of Cardiac Psychology, eds R. Allan and J. Fischer (Washington, DC: American Psychological Association), 115-140.

Nguyen, H. Q., Carrieri-Kohlman, V., Rankin, S. H., Slaughter, R., and Stulbarg, M. S. (2004). Supporting cardiac recovery through eHealth technology. J. Cardiovasc. Nurs. 19, 200-208. doi: 10.1097/00005082-200405000-00009

Pietrabissa, G., Manzoni, G. M., Corti, S., Vegliante, N., Molinari, E., and Castelnuovo, G. (2012). Addressing motivation in globesity treatment: a new challenge for clinical psychology. Front. Psychol. 3:317. doi: 10.3389/fpsyg.2012.00317

Proietti, R., Manzoni, G., Di Biase, L., Castelnuovo, G., Lombardi, L., Fundarò, C., et al. (2012). Closed loop stimulation is effective in improving heart rate and blood pressure response to mental stress: report of a single-chamber pacemaker study in patients with chronotropic incompetent atrial fibrillation. Pacing Clin. Electrophysiol. 35, 990-998. doi: 10.1111/j.1540-8159.2012.03445.x

Proietti, R., Manzoni, G. M., Cravello, L., Castelnuovo, G., Bernier, M. L., and Essebag, V. (2014). Can cardiac resynchronization therapy improve cognitive function? A systematic review. Pacing Clin. Electrophysiol. 37, 520-530. doi: $10.1111 /$ pace. 12328

Riva, G., Castelnuovo, G., and Mantovani, F. (2006). Transformation of flow in rehabilitation: the role of advanced communication technologies. Behav. Res. Methods 38, 237-244. doi: 10.3758/BF03192775

Roth, A., Malov, N., Steinberg, D. M., Yanay, Y., Elizur, M., Tamari, M., et al. (2009). Telemedicine for post-myocardial infarction patients: an observational study. Telemed. J. E. Health 15, 24-30. doi: 10.1089/tmj.2008. 0068

Rozanski, A., Blumenthal, J. A., Davidson, K. W., Saab, P. G., and Kubzansky, L. (2005). The epidemiology, pathophysiology, and management of psychosocial risk factors in cardiac practice: the emerging field of behavioral cardiology. J. Am. Coll. Cardiol. 45, 637-651. doi: 10.1016/j.jacc.2004.12.005

Rubel, P., Fayn, J., Nollo, G., Assanelli, D., Li, B., Restier, L., et al. (2005). Toward personal eHealth in cardiology. Results from the EPI-MEDICS telemedicine project. J. Electrocardiol. 38, 100-106. doi: 10.1016/j.jelectrocard.2005.06.011

Shaffer, F. B., Mccraty, R., and Zerr, C. L. (2014). A healthy heart is not a metronome: an integrative review of the heart's anatomy and heart rate variability. Front. Psychol. 5:1040. doi: 10.3389/fpsyg.2014.01040

Shemesh, E., Yehuda, R., Milo, O., Dinur, I., Rudnick, A., Vered, Z., et al. (2004). Posttraumatic stress, nonadherence, and adverse outcome in survivors of a myocardial infarction. Psychosom. Med. 66, 521-526. doi: 10.1097/01.psy.0000126199.05189.86

Spatola, C. A., Cappella, E. A., Goodwin, C. L., Baruffi, M., Malfatto, G., Facchini, M., et al. (2014a). Development and initial validation of the Cardiovascular Disease Acceptance and Action Questionnaire (CVD-AAQ) in an Italian sample of cardiac patients. Front. Psychol. 5:1284. doi: 10.3389/fpsyg.2014.01284

Spatola, C. A., Manzoni, G. M., Castelnuovo, G., Malfatto, G., Facchini, M., Goodwin, C. L., et al. (2014b). The ACTonHEART study: rationale and design of a randomized controlled clinical trial comparing a brief intervention based on Acceptance and Commitment Therapy to usual secondary prevention care of coronary heart disease. Health Qual. Life Outcomes 12:22. doi: 10.1186/14777525-12-22

Steffen, P. R., Fidalgo, L., Schmuck, D., Tsui, Y., and Brown, T. (2014). Psychotherapy participants show increased physiological responsiveness to a lab stressor relative to matched controls. Front. Psychol. 5:795. doi: 10.3389/fpsyg.2014.00795

Thayer, J. F., and Lane, R. D. (2009). Claude Bernard and the heart-brain connection: further elaboration of a model of neurovisceral integration. Neurosci. Biobehav. Rev. 33, 81-88. doi: 10.1016/j.neubiorev.2008.08.004

Warner, C. H., Warner, C. M., Appenzeller, G. N., and Hoge, C. W. (2013) Identifying and managing posttraumatic stress disorder. Am. Fam. Physician $88,827-834$.

Wood, S. K. (2014). Cardiac autonomic imbalance by social stress in rodents: understanding putative biomarkers. Front. Psychol. 5:950. doi: 10.3389/fpsyg.2014.00950

Conflict of Interest Statement: The authors declare that the research was conducted in the absence of any commercial or financial relationships that could be construed as a potential conflict of interest.

Copyright (C) 2015 Ginsberg, Pietrabissa, Manzoni and Castelnuovo. This is an openaccess article distributed under the terms of the Creative Commons Attribution License (CC BY). The use, distribution or reproduction in other forums is permitted, provided the original author(s) or licensor are credited and that the original publication in this journal is cited, in accordance with accepted academic practice. No use, distribution or reproduction is permitted which does not comply with these terms. 